\title{
Digitized Ethnic Hate Speech: Understanding Effects of Digital Media Hate Speech on Citizen Journalism in Kenya
}

\author{
Stephen Gichuhi Kimotho \\ United States International University, Africa \\ E-mail: sgkimotho@usiu.ac.ke \\ Rahab Njeri Nyaga (Corresponding author) \\ Languages and Linguistics, Pan Africa Christian University, Africa \\ E-mail: rahab.nyaga@pacuniversity.ac.ke
}

Doi:10.7575/aiac.alls.v.7n.3p.189

URL: http://dx.doi.org/10.7575/aiac.alls.v.7n.3p.189
Received: 15/01/2016

Accepted: 26/03/2016

\begin{abstract}
Ethnicity in Kenya permeates all spheres of life. However, it is in politics that ethnicity is most visible. Election time in Kenya often leads to ethnic competition and hatred, often expressed through various media. Ethnic hate speech characterized the 2007 general elections in party rallies and through text messages, emails, posters and leaflets. This resulted in widespread skirmishes that left over 1200 people dead, and many displaced (KNHRC, 2008). In 2013, however, the new battle zone was the war of words on social media platform. More than any other time in Kenyan history, Kenyans poured vitriolic ethnic hate speech through digital media like Facebook, tweeter and blogs. Although scholars have studied the role and effects of the mainstream media like television and radio in proliferating the ethnic hate speech in Kenya (Michael Chege, 2008; Goldstein \& Rotich, 2008a; Ismail \& Deane, 2008; Jacqueline Klopp \& Prisca Kamungi, 2007), little has been done in regard to social media. This paper investigated the nature of digitized hate speech by: describing the forms of ethnic hate speech on social media in Kenya; the effects of ethnic hate speech on Kenyan's perception of ethnic entities; ethnic conflict and ethics of citizen journalism. This study adopted a descriptive interpretive design, and utilized Austin's Speech Act Theory, which explains use of language to achieve desired purposes and direct behaviour (Tarhom \& Miracle, 2013). Content published between January and April 2013 from six purposefully identified blogs was analysed. Questionnaires were used to collect data from university students as they form a good sample of Kenyan population, are most active on social media and are drawn from all parts of the country. Qualitative data were analysed using NVIVO 10 software, while responses from the questionnaire were analysed using IBM SPSS version 21. The findings indicated that Facebook and Twitter were the main platforms used to express ethnic hatred. Hate speech incited hatred and conflict for political gain. Ethical issues raised included moral subordination and incivility.
\end{abstract}

Keywords: hate speech, Ethnicity, Ethnic conflict, digital media, social media, stereotypes, incivility, speech acts, illocutionary acts, political conflicts, moral subordination

\section{Introduction}

Ethnic Conflicts is normally indicative of lack of dialogue and goodwill between the disputing parties. When conflicting views are expressed through the media, the resulting visibility and position taking only escalates the conflict. Availability of digital media through which every citizen can express their views without regulation or restriction, has contributed to the increased expression of ethnic hate speech through the digital platform. Today, the diffusion of new technology, access to niche digital and traditional mass media, and the rise of an informed, active populace have revived the role of the citizen journalism and of grassroots communication (Musa \& Willis, 2014).

Kenya is made up of 42 tribes and ethnicity permeates all spheres of life of most Kenyans. Tribal identification has been enculturated into the Kenyan psyche to an extent that to truly know a Kenyan, you need to connect him or her to an ethnic group. One way in which ethnicity has been played out is through tribal stereotyping. Tribal stereotyping is often found in social jokes and in political pronouncements.

The influence of digital technologies is changing human actions and beliefs, as well as the construction of our social reality. This paper seeks, also, to examine the role of citizen journalism in propagating ethnic hate speech among Kenyans. It describes the nature of ethnic hate speech, the influences of ethnic hate speech on Kenyans' perception of ethnic entities, and the ethical concerns around digitized ethnic hate speech in Kenya. To do this, the authors carried out research that analysed content of conversations from eight purposefully sampled social media sites to identify expressions of hate speech. Additionally, university students were interviewed to get their views and experiences with digitized ethnic hate speech. This paper also presents theories considered in discussing ethnic hate speech and reviews literature on ethnic hate speech from across the globe. 
In today's technologically advanced world, the conversations go on at all times and the communicators increase with each interaction. While this has the positive aspects, a very dark side has also emerged. This is communication of negative aspects like ethnic hate speech. Umati report of 2013, dubbed "Monitoring Online Dangerous Speech" notes that Kenya has a history of hate speech in the political arena (Umati, 2013). With the advent of the digital era, proliferation of digitized hate speech seemed to acquire new life and a new dimension (Martin Chege, 2008). Ethnicity seems a key consideration in many aspects of life in Kenya like politics, education and even business. Such an environment is fertile ground for ethnic competition and strife, which often finds expression in hate speech.

Though the general elections of 2013 in Kenya witnessed a heated political scenario, only few incidences of violence were reported. However, a different kind of battle zone had been borne: the war of words on social media platform. More than any other time in Kenyan history, Kenyans poured vitriolic ethnic hate speech through digital media like Facebook, tweeter and blogs.

While scholars have devoted significant effort in understanding the role and impacts of the mainstream media like television and radio in proliferating the ethnic hate speech in Kenya (Goldstein \& Rotich, 2008b; J Klopp \& P Kamungi, 2007), there is a dearth of information on the nature and effects of ethnic hate speech, proliferated through the digital media in Kenya. This kind of hate speech, however, continues to be a serious social problem in Kenya to date.

Tribal stereotyping often found in social jokes and politics forms the main platforms through which negative ethnicity manifest itself. Ethnicity has apparently become an important criterion in vetting public servants before they get jobs in Kenya. The concept, ethnic balancing is used to justify giving plum government jobs to candidates from different ethnic backgrounds. This is done in an effort to consider varied ethnic interests represented in the country. Such actions consider ethnicity before qualifications. Hate speech has been known also to lead to violence and death. The animosity fuelled by the politically instigated ethnic hate speech in 2007 , resulted in widespread skirmishes that led to massive displacement, and in loss of lives and livelihoods. About 1,200 people lost their lives and 350,000 people were displaced and property worth millions of shillings destroyed (KNHRC, 2008).

A big problem in Kenya has been politicizing ethnicity to capture public office. Politicians seem to have perfected the art of appealing to and mobilizing ethnic support during election campaigns. Political power in Kenya implies economic power. The perception therefore, encouraged by the politicians, is that an ethnic group benefits economically when their man gets a political office. Appeals to own ethnic groups for political support and attacks on opponents and their ethnic groups result in polarization along ethnic lines. All these play out in the full glare of the media and once media reports go out, more of the citizens are sucked in and take sides. During 2013 political elections, digital media platforms were widely used in Kenya. Citizen journalists found endless ways of expressing themselves through the digital media. Virtually anybody could express themselves at any time and on any topic. This is what is popularly called citizen journalism. Citizen journalism is defined here as citizens "playing an active role in the process of collecting, reporting, analysing and (distributing) news and information"(Allan \& Thorsen, 2009).

Citizen journalism played a significant role in ontogeny of ethnic hatred and how fast it spread among the Kenyans in 2013. The public were bombarded not only with hateful and derogatory depictions of politicians and of ethnic groups, but also with the idea that it was acceptable to express hatred electronically and share it publically. The next section presents definitions and concepts used in this paper in our discussions about digitized hate speech in Kenya.

\subsubsection{Definition of Ethnicity}

Ethnicity is an umbrella term which subsumes a variety of factors and processes, some of which have little in common. Aspects that have been considered in defining ethnicity have included historical, geographical locations, political moral, religion, social class, and language. Although scholars have not built consensus on its meaning, ethnicity as conceived by many theorists consist of a group of individuals who are seen to, and conceive of themselves as being different from other groups of individuals. This difference is manifested in how they dress, language, social customs, and mores etc. These visible differences are cultural symbols which are seen as part of the ethnic community and as belonging to them as a group. In other words, the visible differences attributed to the group by others and by themselves. Ethnic differentiations and linguistic cleavages are often essential considerations for the citizens when endorsing political leaders, parties and social movements. Communities use these perceived ethnic differences to form ethnic conglomerates, label and attack their perceived enemies from different ethnic groups during ethnic conflicts (RepublicofKenya, 2008).

Ethnicity has also been defined contextually. In the wider government and institutional contexts, ethnicity usually denotes race. It is about someone's cultural background or where they came from. There is a group of scholars like Anderson, who argues that ethnic groups are socially constructed and imagined communities, which are subject to negotiation and re-negotiation (Anderson, 2006). However, this paper subscribes to the school of thought that includes scholars like Isajiw, which sees the meaning of the concept of ethnicity as depending on the meaning of several other concepts, particularly those of ethnic group and ethnic identity (Isajiw, 1993).

Isajiw views the concept of ethnic group as the most basic form, from which the others are derived. He adds that ethnicity itself is an abstract concept, which includes an implicit reference to both collective and individual aspects of the phenomenon. There are several basic dimensions to ethnicity at either the collective or the individual level. It can be said to possess both an objective and a subjective dimension. The objective aspects are those that can be observed as 
facts in the existence of institutions, including that of kinship and descent, and in the overt behaviour patterns of individuals and groups (Macfarlane et al., 2007). The subjective aspects comprise attitudes, values, and preconceptions whose meaning must be interpreted in the context of communication (Hout, 2008).

\subsubsection{Aspects of Ethnicity}

Ethnicity is a multifaceted and changing phenomenon and can be viewed in different ways. Various scholars have considered different aspects like country of birth, nationality, language spoken at home, skin colour (an aspect for consideration for some and not for others), national/geographical origin and religion. What seems to be generally accepted, however, is that ethnicity includes all these aspects, and others, in combination. This study focused on two key aspects of ethnicity: the political and the moral.

\subsubsection{Political aspects of ethnicity}

Under the political aspect, the focus was on digitized ethnic hate messages related to the political activities of the country. These occur at the national, political party or tribal levels and particularly during or following political activities like elections or sharing of national resources. Ethnicity is often at the centre of politics in divided societies (Montalvo \& Reynal-Querol, 2010). Sambanis consolidates this argument by pointing out that ethnic civil wars are usually a result of political rather than economic grievances (Sambanis, 2004). Ethnic politics are largely concerned with protection of rights, privileges and other benefits for members. In Kenya, the Waki inquiry into the post-election violence established that claims of ethnic favouritism in distribution of resources like land and public service jobs, among other resources, featured strongly as some of the root causes of the 2007 post-election violence (RepublicofKenya, 2008).

\subsubsection{Moral aspects of ethnicity}

Moral aspect of ethnicity considers stereotypes, perceptions and prejudice. Conflicts over moral issues tend to be intractable and long-lasting since the substantive issues are a matter of rigidly held moral beliefs that are difficult to change. The moral dimension of identity involves a sense of obligation to the group. In general, such feelings have to do with the importance that a person attaches to his or her community and the implications that the group has for the person's behaviour. These would include such elements as the importance of teaching the group's ancestral language to one's children, marrying within the group, or helping other members to find a job. The sense of obligation accounts for the commitment that an individual has to the group and the group solidarity that results (Isajiw, 1993). It is such obligation to the group that results in blind support for one's ethnic group, even when the voice of reason would dictate otherwise. Ethical consideration towards other ethnic group seem subsumed by loyalty to one's ethnic group and the tendency is to devalue other groups and place the issues of one's ethnic group as the only ones worth considering.

\subsubsection{Hate Speech}

Hate speech, has been widely debated and scrutinized in both political and academic circles, but a universally agreed definition of hate speech does not exist (Stakic, 2011). Therefore, any discussion of hate speech requires definition of the term. In this study we shall adopt 1997's Committee of Ministers of the Council of Europe (COE) definition of Hate speech (Timofeeva, 2002).

Hate speech, refers to all forms of expression which spread, incite, promote or justify racial hatred, xenophobia, anti-Semitism or other forms of hatred based on intolerance, including: intolerance expressed by aggressive nationalism and ethnocentrism, discrimination and hostility against minorities, migrants and people of immigrant origin.

There are two elements that appear to be common to a variety of views; first, hate speech is directed to a person or a group of persons who are considered by some to be inferior on the basis of some characteristic that is constitutive to their identity and, generally, innate (e.g. race, ethnicity, sexual orientation etc.); secondly, hate speech is intended to incite violence, discriminatory treatment, or the offence to human dignity of targeted person(s) (Stakic, 2011).

Hate speech includes things like identity-prejudicial abuse and harassment, certain uses of slurs and epithets, some extremist political and religious speeches (e.g. statements to the effect that all non-Kalenjin communities living in Rift valley were 'Madoadoa' (a Swahili slur which means 'stains on a garment'). The slur was used during 2007 postelection violence to instigate tribal hate and violence against such ethnic groups), and certain displays of hate symbols (e.g. burning crosses). In this paper, activities are classified as hate speech if, and insofar as, they convey the idea that belonging to a particular social group warrants someone's being held in or treated with contempt.

Many scholars seem to agree that hate speech expresses, advocates, encourages, promotes or incites hatred of a group of individuals distinguished by a particular feature or set of features (Hernández, 2011; Townsend, 2014; Traum, 2014). It is a term that is used to refer to verbal conduct - and other symbolic, communicative action - which wilfully "expresses intense antipathy towards some group or towards an individual on the basis of membership in some group"(Simpson, 2013). Therefore, hate speech is not necessarily verbal act, it can also be written or in any other form of non-verbal communication. This clarification is important because most of the digitized forms of hate speech that will be subject of this paper are written or in other symbolic communicative actions.

\subsubsection{Digitized hate speech}

Digitized hate speech may be defined as any use of electronic communications technology to spread ethnic hate messages or information. These electronic communications technologies include the Internet (i.e., Web-sites, social 
networking sites, blogs, instagram, instant messages, and e-mail) as well as other computer- and cell phone-based information technologies (such as WhatsApp).

Today more than ever in the history of Kenya, persons with disparate goals can access and affect large audiences through these technologies. Both those seeking social improvement and those promoting ethnic hate can now increase the magnitude, diversity, and location of their audiences through the digital media platforms (Tsesis, 2001). Though digital media platforms have numerous modes of transmission and are tremendously growing every day, this paper limited itself to Facebook pages because they were chiefly used in spreading hate messages before and after 2013 general election (Umati, 2013).

Alongside the globalization of technology, there has been an incremental rise in the number of online ethnic hate groups and hate related activities taking place in cyberspace (Banks, 2010). This may also be attributed to the tremendous growth of internet. International Communications Union estimates that there could be as many as 3 billion global internet users, with many of them using mobile-only connections (Kante, 2014). By 2014 social network users were estimated at 1.9 billion, with at least $22 \%$ of them accessing social media on a mobile device.

In Kenya, by close of 2014, the number of estimated internet users stood at 23.2 million (about 52.7\% of the total population). By close of 2014 mobile subscriptions in Kenya had hit 32.8 million, about $74 \%$ of the total population. Research report by The Digital Rand on "The State of Social Media in Kenya" indicated that Facebook dominates Kenya's social media scene with 3.8 million users. Far behind them is Linked-in with 1.5 million users, Twitter with 650,000 users and Google+ with 350,000 (TheDigitalRandReport, 2014).

\section{Theoretical Frame work}

Language does not only define an ethnic group but also, to a big extent, language is a means of organizing people and directing their behaviour (Ayeomoni \& Akinkuolere, 2012). People use language for various reasons to persuade, dissuade or even criticize. This paper is premised on the fact that hate speech is a form of language that is meant to achieve some end purpose. Therefore, understanding what people say, and how what they say may impact on the lives of those they address, is fundamental to understanding ethnic hate speech.

\subsection{Speech Act Theory and Hate Speech}

This study utilized Austin's Speech Act Theory (SAT). SAT was deemed suitable because it explains how language (spoken or written) could be used to achieve preconceived intentions. Speech Act Theory argues that to say something is to do something. In other words, "we do things, not only say things, with words" (Austin, 1975). For instance, in a wedding when a man says, "I do," he is not only describing his mental state that he is willing to marry the woman, rather, at that moment, his speech is an act of taking the woman as his wife. Austin further elaborated on his theory by pointing out that there are at least three components in a speech-act: Locutionary act, Illocutionary act, and Perlocutionary act.

Speaker can simultaneously perform three acts in issuing an utterance: the locutionary act is the act of saying something with a certain sense and reference; the illocutionary act is the act performed in saying something, i.e. the act named and identified by the explicit performative verb. The perlocutionary act is the act performed by, or as a consequence of, saying something (Searle \& Vanderveken, 2005).

It is the illocutionary act that is the focus of Austin's attention because it is the essence of the speech act. An illocutionary act is a conventional linguistic act, whereas a perlocutionary act is a non -conventional non-linguistic one. While the first is under the control of the speaker, the second is not. For example, I may wish to change my audience's opinions about a certain ethnic group through certain hate message: this would be my perlocutionary aim, and it could fail to come true even if all the conditions for the felicity of the performative were met. This is because the specific perlocutionary effects which are actually produced in any given case depend on the particular context in which my speech act is uttered. Thus, if my audience is very impressionable, it may be easier for my perlocutionary aim to be achieved. On the other hand, my perlocutionary aim may fail even if the utterance is an illocutionary success (Zanghellini, 2003).

Towards the end of his book, Austin attempts a classification of illocutionary verbs using the explicit performative test and a concise dictionary. He comes up with five main classes or categories: (Verdictives, excercitives, commissives, behabitives, expositives). Many scholars, have criticized Austin's classification as not complete and modified or developed their own classifications. One of the most widely used classification is Searle's. Searle's classification attempt to give a more comprehensive picture of illocutionary acts. Here is Searle's classification for types of illocutions:

a. Assertive: an illocutionary act that represents a state of affairs. These are statements that describe a state of affairs in the world which could be true or false. They commit a speaker to the truth of the expressed proposition, such as stating, claiming, hypothesizing, describing, telling, insisting, suggesting, asserting, or swearing that something is the case.

b. Directive: an illocutionary act for getting the addressee to do something. These are statements that compel or make another person's action fit the propositional element. It is usually used to give order thereby causing the hearer to take a particular action, request, command or advice like ordering, commanding, daring, defying or challenging. 
c. Commissive: these statements commit the speaker to certain future action. It could be in the form of a promise. Examples include promising, threatening, intending, and vowing to do or to refrain from doing something.

d. Expressive: an illocutionary act that expresses the mental state of the speaker about an event presumed to be true. Such statements are used to express the psychological state about a state of affairs specified in the propositional content like congratulating, thanking, deploring, condoling, welcoming and apologizing.

e. Declaration: an illocutionary act that brings into existence the state of affairs to which it refers. These statements are used to say something and make it so, such as pronouncing someone guilty and declaring a war. Examples include blessing, firing, baptizing, bidding, passing sentence or excommunicating.

Whenever a speaker utters a sentence in an appropriate context with certain intentions, he performs one or more illocutionary acts. In general, an illocutionary act consists of an illocutionary force F and a propositional content P. For example, the two utterances "You will leave the room" and "Leave the room!" have the same propositional content, namely that you will leave the room; but characteristically the first of these has the illocutionary force of a prediction and the second has the illocutionary force of an order (Searle \& Vanderveken, 2005). This paper focused on the illocutionary force since it brings out the intention of the authors of digitized hate speech. In fact, ethnic hate-mongers are likely to desire the realization of changes in the beliefs, thoughts and feelings of their audiences - that is, they desire the production of specific perlocutionary results. This paper, therefore, endeavoured to answer the following specific questions: i) What types of illocutionary acts are found in digitized ethnic hate speech on social media in Kenya? ii) What illocutionary force do these illocutionary acts found in digitized ethnic hate speech on social media in Kenya, hold?

\section{Methodology}

The study adopted a descriptive interpretive design utilizing qualitative and quantitative approaches. We employed meaning-based as well as statistical forms of data analysis. Purposive sampling was used to pick two private and two public universities in Kenya to ensure a broad spectrum of students, with diverse ethnic background was covered. The university students form a good sample of Kenyan population because they are most active on social media, they are drawn from all parts of the country, and they are above 18 years. Once at the institutions, stratified convenience sampling design was used to ensure views of both undergraduate and postgraduate students were captured.

Questionnaires were administered to students in the four universities. This was done in class settings. The purpose of the study was first explained and the students requested to participate. Those willing completed the questionnaire and submitted them at the end of the class session.

Qualitative data was collected from eight purposefully sampled social network sites. The sites are: The Gor Mahia is not a club, It's a Lifestyle! but Do We Say; I dont hate Ruto, Uhuru and G7 group. I only hate their hypocricy; Jubilee Coalition Youth League; Kenyans Agaisnt Uhuruto 2013; Nyumba Ya Mumbi 100\% voter turnout drive; Raila Odinga Won 2013 Presidential Election; STOP RAILA ODINGA NOW!!!!!; Uhuru is President Luos will have their dicks... NOT Another Kikuyu President Please.

We used NCapture to collect the illocutionary speech acts from the sites. Illocutionary speech acts were preferred because they form the minimal units of human communication (Searle \& Vanderveken, 2005). They exist in many forms including: statements, questions, commands, promises, and apologies among others.

The speech acts from the eight sites were captured in the form of datasets which were labeled after these sited. The eight hate sites were all public facebook pages. The preference for facebook hate sites was informed by previous studies on hate speech in Kenya around that time (particularly Umati Report, 2013), which indicated that more than 90\% ethnic hate messages were on facebook.

The datasets from the eight sites yielded 35,915 speech acts. This data was organized and stored in NVIVO 10 data base for easy retrieval and analysis. Only data appearing on these sites between 4th November 2012 (the day Independent Electoral and Boundaries Commission (IEBC) published the notice of Election Period), and 16 May 2013 (exactly one month after final judgement on Presidential Election Petition 2013), was analyzed. The election petition, filed at the Supreme Court of Kenya on the 16th of March 2013, was aimed at declaring Kenya's presidential election 2013 null and void. During this particular period (November 2012 - May 2013) the political events saw the cases of hate speech on digital platform rise to a magnitude never witnesses before in Kenya (Umati Report, 2013).

\section{Findings of the Study}

\subsection{Nature of Ethnic Hate Speech on Digital Media in Kenya}

It emerged from the data that, the digital platforms mostly used for hate speech in were Facebook, twitter and personal blogs and instagram and they accounted for 96.6 of total posts. This compares with the Umati report which indicated that over $90 \%$ of all online inflammatory speech captured by Umati was on Facebook, making it the highest source of such content. Digitized hate speech in Kenya is a frequent occurrence to many Kenyans. It emerged that at least $60.4 \%$ of the respondents' experience digitized hate speech either often or very often. Author of hate speech in Kenya seem to focus on four major areas: Ethnicity, Religion, politics and gender forms of hate. Of the sampled respondents $24.8 \%$ admitted that they have been targets of digitized hate speech. Of those who had been targets of digitized hate speech, $41.3 \%$ were targeted for their ethnicity, $20.7 \%$ for their political inclination, $15.7 \%$ for gender and $12.4 \%$ for religious affiliations. Ethnicity therefore is therefore the main focus of hate speech in Kenya. 
Using the speech act theory, the authors analysed the data from the social media sites to establish the types of illocutionary acts used in digitized ethnic hate speech. The analysis of the data indicates all the types of illocutionary act as described by Sealre's were used but to a varying degrees. Expressives were the most heavily used illocutionary acts and constituting $55.4 \%$ of all the illocutionary acts that were coded. Declaratives were second most heavily used illocutionary act constituting 21.4\%; while Directives, Assertives, and Commissives had 14.2\%, 4.5\%, and 4.4\% respectively. According to Speech act theory, each of these illocutionary acts contains what Austin called illocutionary force or the intention of the source of these speech acts. In the next section, the perceived intentions of the authors of digitized hate speech were examined.

\subsection{Perceived intention of the authors of digitized hate speech}

Speech act theory frame work was used to organize and categorize the emerging themes and subthemes. Therefore, the theory of Speech Acts served as the spread sheet for the analysis and evaluation of the selected incidences of digitized hate speech.

Expressives had four major types of illocutionary forces: criticizing, taunting, condemning, demeaning, dismissing, expressing anger or annoyance and use of swear words. Although there were a few critiques that were target on individual commentators, most of the critiques seemed to target the whole ethnic group rather. For instance, there were numerous statements meant to reflect that a whole ethnic group is "useless", stone throwers or violent, or lazy. For instance: "I want all Kikuyus to be re-circumcised and be told the real meaning of circumcision" or "Jaluo are stupid ugly human beings who never accept defeat and usually throw stones and are not circumcised!"

Illocution acts expressing anger and annoyance were characteristically introduced or followed by an interjection "Nkt." Nkt is a textual representation of a popular clicking sound made by Kenyans to show disapproval, annoyance or discontent (Tully \& Ekdale, 2012). For instance, this author uses this to express anger, annoyance and contempt for some ethnic group: "aki i hate kikuyus n kales.nkt" (For real I hate Kikuyus and Kalenjins nkt); Nkt!! we acha chuki na kikuyu u r tribalistic shindwe ww...bure kabsa...nktest!!! (Nkt! You stop hating Kikuyus. You are tribal. May you be defeated! You are very useless...nktest). Interesting, 'nkt' was frequently conjugated to "nktest" to denote the intensity of the anger of the author

Demeaning and dismissive speech acts also featured in most of hate messages in these categories. Many of the demeaning messages seemed to question the intellectual capacity of certain ethnic groups. Most of them were laced with insults mentioning the brain or mind or thinking. For instance: "Jaluos are very thick do they really have brain that functions?"; "Did i jst hear sam1 say Kenya ni ya okuyu??wana akili ndogo kama ya jiggers!! (Did I just hear someone say Kenya belongs to Kikuyus? They (Kikuyus) have very small brains equivalent to jiggers' brains)

Declaratives were the second most utilized speech acts. They were used to attain different kinds of illocutionary force. Two major intentions emanated from the data: insulting, and blaming. Illocutionary acts intended to insult constituted $76.3 \%$, while those intended to blame constituted $23.7 \%$ of all the declaratives. Some insults that were used were largely informed by common ethnic stereotypes known to many Kenyans. For instance, there were some that referenced Kikuyus as thieves: For example: "a thief just got killed in my neighbourhood. What made the killing even sweeter was that the poor thing was a kikuyu. Kikuyus are all thieves anyway." There are other insults that referenced Luo community as violent and stone throwers. For example: "Jaluo jeuris who are you to judge? style up professional stone throwers ...nktest [Arrogant Luos, who are you to judge?...style up professional stone throwers... nktest].

Another category of insults intended to humiliate the target ethnic communities. Such insults include what the authors have called "Jigger insults" (describing a community as jigger laden community). Jigger, scientifically known as Tunga Penetrans is an ectoparasite that causes a skin disease called Tungiasis. It is largely perceived by many communities that tungiasis is brought by laziness and dirtiness (Kimotho, 2013). Most of the jigger insults were mainly directed at Kikuyu ethnic group perhaps because of the high preference of this disease in central Kenya, where the Kikuyu ethnic group lives. For instance: "For these Kikuyus, the jiggers in their brains need more prayers than the jiggers in their feet!"

Finally, the data yielded substantial illocutionary acts meant to blame certain ethnic communities for different reasons. For instance, there were illocutionary acts that intended to blame certain ethnic groups for selfishness. The following example captures this type: "Luos are so selfish! Must you always win even when you have clearly lost? Grow up people am so frustrated by your behaviour Nkt!" Most of the other illocutionary acts intended to blame were introduced by "we-versus-them" distinction. Use of "we" versus "them" Language is meant to promote distance, set up we versus them and superior versus inferior relationships, and carry connotations regarding values, expectations, skills, and abilities (good versus bad, strong versus weak, fast versus slow, high versus low expectations, and well versus sick) (Kailes, 2010).

Directives were the third most used illocutionary acts according to the data. The main aim of these acts is to get the addressee to do something. Eight forms of Directives emanated from the data: challenging, commanding, admonishing, begging, ordering, urging, advising, and dismissing. Ordering had the highest number of illocutionary acts and accounted for $30.0 \%$ of all directives. Three main categories of illocutionary acts intentioned for ordering were: "Must do", "don't do" and "need to do" speech acts. The most prominent of these were the "must do" acts. The following example illustrates how such acts were framed by the authors calling people to violence: "liberation is a must! Blood must be shed... we go...we goooo... 
The least used directives were those that were intentioned to urge. They constituted only $0.96 \%$ of all directives. Mainly they urged Kenyans in general to maintain peace and avoid violence as illustrated by the following example: " $I$ urge all Kenyans, and specifically Kalenjin, not to get it wrong. Our plight as a community is well taken where I am, than where you asked to go, out of anger and pride."

Assertives: Assertives tell people how things are. Assertive speech acts are definitions, descriptions, assertions, statements, and so on; and can be true or false. $72.2 \%$ of the Assertives were intended to state some perceived truths. For instance, many of the Assertives made some claims meant to reflect the target ethnic groups in negative light. For instance, one of the hate speech acts declared, "Jaluo jinga! thats Why u'll never rule Kenya" (Luo people are foolish! That is why they will never rule Kenya). Another one, this time referring to Kikuyu community, commented, "@Martin like all kikuyus, you are an ungrateful idiot who thinks Kenya is for Kikuyus only. You are as foolish as the rest of your tribesmen..." The main intention of such authors is to belittle and demean the whole ethnic group. Such assertions were also meant to make member of such ethnic group feel like they are to blame for the prevailing political phenomenon. If the following comment is anything to go by, then such form of hate speech affected the readers in diverse ways. "Wajaluo sisi wote ni MAUMBWA!! Thats why we are the MOST HATED tribe on earth. Reason UJINGA WA AKILI.. I wish $i$ was a kyuk or kale. BULLSHIT!!" (All of us Luos are dogs! That is why we are the most hated tribe on earth. Reason we are foolish in our minds...I wish I was born a Kikuyu or Kalenjin. Bullshit"). From the findings of this study, many of the assertives were intended to persuade the target audience. The following example illustrates this fact: "Freedom is never voluntarily given by the oppressor; it must be demanded by the oppressed. Let's join hands to fight for justice." Descriptive assertives stated some perceived truths. Most of these perceived truths borrow from the existing ethnic stereotypes and they included: Luos are Stone throwers (violent); Luos are Dirty; Kikuyus are Land grabbers; Kikuyus are Shrewd; and Kikuyus are selfish.

Commissives commit the speaker to certain future action. It could be in the form of a promise, agreeing, guaranteeing, inviting, offering, swearing, and threatening to do something in future. Two types of commissives emerged from the data: Threatening and swearing. Of the two, types, swearing were the most prominent constituting $65.6 \%$ of all the commissives. Most of the commissives used the phrase "will never" perhaps as author's way of demonstrating resolve. The following example clearly illustrates this:

"...this is why Jaluo will NEVER rule this land! How can u carry U.S. flag and call it ua own? We $r$ not ready 2 go back 2 colonialism! UHURU 4REVA. You can call Raila ur prezo 2 ur graves but he will never be as long as he lives. Warmonger.....yu will never rule this country....cursed man"

Through every hate message authors publish on the digital platform, they perform one or more illocutionary act. Additionally, every illocutionary act consists of an illocutionary force F (the intention the author hopes to accomplish through the illocutionary act they publish). A post like "We must kill these peoples" has an illocutionary force of instruction or command (Searle \& Vanderveken, 2005).

\subsection{Effect of hate speech on recipients}

The study also sought to establish from the respondents, the various ways in which digitized ethnic hate speech may affect or influence behaviours or beliefs of the consumers of digitized ethnic hate speech. In summary, the authors established that over half of the respondents $(50.5 \%)$ stated that reading hate messages targeted at their own ethnic group on the social media made them feel bad about themselves, while $47.9 \%$ however indicated that it did not. A great majority $(86.7 \%)$ also indicated that reading hate speech messages on social media made them feel bad about the authors of such hate messages. In addition, more than half of the respondents also indicated that reading such hate messages did not make them feel as bad about the community of the source $(56.7 \%)$.

At least $90.7 \%$ of the respondents believed that hate speech messages on social media influence people's judgement about the target ethnic groups. On the choice of a social media friend, $68.8 \%$ of all respondents indicated that stereotypes spread through digitized hate messages do not influence their choice of social media friends. A total of $30.4 \%$, however, admitted that such digitized hate messages influenced their decision while picking social media friends.

Does reading hate messages on social media make one get stressed. More than half of the respondents (57\%) indicated that they were not stressed after reading hate messages while $42.1 \%$ were. This could be an indication that Kenyans were learning not to take hate speech personally. There are however statistically significant percentage of Kenyans who still find digitized hate messages stressful.

One of the most appalling finding in this study is that $90.7 \%$ of the respondents believed that hate speech messages on social media influence people's judgement about the target ethnic groups. This is important because it demonstrates that digitized hate messages have a potential of shaping the beliefs and conceptions of ethnic groups and how they should view or treat other ethnic groups.

In an interesting twist that could demonstrate that Kenyans largely perceive themselves from an individualistic rather than a communalistic perspective, $68.8 \%$ of all respondents indicated that stereotypes spread through digitized hate messages do not influence their choice of social media friends. A total of $30.4 \%$, however, admitted that such digitized hate messages influenced their decision while picking social media friends. 
One of the controversies digitized ethnic hate speech raises is on ethics of hate speech in citizen journalism. The debate on ethics and hate speech has been ongoing for decades, yet there is little hope for consensus (Altman, 1993; Rosenfeld, 2002). For instance, how do we decide what lies within, and what falls outside, the ethical bounds of public discourse? The questionnaire respondents were divided on whether ethnic hate speech is ethical or not. A total of $71.2 \%$ felt that it is not ethical while $22.6 \%$ found nothing wrong with it. This implies that the hate speech advocates will always have supporters and encouragers. A majority of respondents (88.8\%) however did not approve use of online platforms to express hatred or disapproval of certain ethnic groups. This is unethical and offensive to people of ordinary sensibilities.

A tweet posted by Bitange Ndemo, then permanent secretary (PS) at the Ministry of Information and Communications, on March 10, 2013 confirmed that indeed there was hatred on social media, enough to get the government worried. "Good morning. We've noted your concerns regarding hate speech being propagated on social media, and we are working overdrive to control it," tweeted the PS. The government considered expression of hate through social media unacceptable and this raises the issue of the acceptability of citizen journalism and erosion of the rights of others as one exercises their perceived right to free speech.

\subsection{Influence of Hate Speech}

What raises concern is that $90.7 \%$ of the respondents believed that hate messages on social media influence people's judgement about the ethnic group's portrayal on digital media. The respondents $(50.5 \%)$ stated that reading hate messages against their own ethnic group on social media made them feel bad about themselves.

Scholars in the area of hate speech seem to agree that hate speech is not only very hurtful, but also potentially dangerous. As Goldston puts it, "hate speech stigmatizes its target by ascribing to it a set of constitutive qualities that are widely viewed as highly undesirable" (Goldston, 2002). It is a powerful weapon which can be used to marginalize, intimidate and demean still further those who have already been rendered vulnerable by society. The ease and global reach of the internet, makes it more important than ever to understand the digitized hate speech.

\subsection{Moral subordination}

Moral subordination and incivility are problems that have preoccupied scholars of hate speech and morality for a long time (Boeckmann \& Turpin-Petrosino, 2002; Orbach, 2012; Waldron, 2012). In this study we argue that treating persons as moral subordinates based on their ethnic differentiation is wrong. Before we explain this, there is need to define what we mean by moral subordination. Treating persons as moral subordinate means treating them in a way that takes their interests to be intrinsically less important, and their lives inherently less valuable, than the interests and lives of those who belong to some reference group (Altman, 1993). There are many ways of treating people as moral subordinates. These include practice of ethnic segregation, in which some conditions are imposed on some ethnic groups with a purpose of putting such an ethnic group in its (supposedly) proper place (Perry, 2012).

The authors of this paper believe that the language of ethnic slurs and epithets provides wholly conventional ways of treating people as moral subordinates. Phrases such as 'dirty Jaluos', 'stone throwers', 'Kikuyu thieves', and 'Kikuyu rapists' are verbal instruments of subordination. These phrases are not only used to express hatred or contempt for the target group but also to "put them in their place," that is to treat them as having inferior moral standing. Putting people down this way or using ethnic slurs and epithets of hate speech harms their dignity. 'Dignity' is here defined as the social standing or the fundamentals of basic reputation that entitle [a person or persons] to be treated as equals in the ordinary operations of society" (Cohen-Almagor, 2013). Cohen-Almagor argues that dignity "is a matter of status- one's status as a member of society in good standing - and it generates demands for recognition and for treatment in accord with that status (Cohen-Almagor, 2013)."

\subsection{Incivility}

Incivility, refers to any "speech or action that is disrespectful or rude" (Berger, 2003). Clark expands this definition by noting that incivility indicates "disregard and insolence for others, causing an atmosphere of disrespect, conflict, and stress" (Clark, 2008). Incivility came in different forms as reflected in the data. There were different forms of curses and insults targeted on individuals and ethnic groups. For instance, Insults that referenced other ethnic communities as foolish, thick, or stupid constituted $43.1 \%$ of all the insults. The authors of hate messages also used animal images including: dogs, hyenas, monkeys, snakes, rats and mongrels. "Use of epithets particularly "fuck" and insults related to human anatomy (particularly male and female genitals) accounted for $14.6 \%$ of all insults and curses used. This study established that uncivil language is pervasive and widespread on digital media used in Kenya and authors of hate speech use it as a tool of demeaning and disparaging the target individuals or communities.

\section{Discussions}

The finding of this study seems to largely agree with previous studies on hate speech which indicate that hate speech is harmful and injurious to the victims (Reddy, 2002; Rosenfeld, 2002; Waldron, 2012). Hate speech is alleged to be harmful in several ways. First, it is insulting, and insults are psychologically wounding and cause emotional distress (Alexander, 2000).

This study's findings also reveal that more than half of the respondents felt bad about themselves after reading hate messages targeted at their own ethnic group on the social media would only mean that hate speech messages had significant negative impacts on individuals' identity and self-confidence. Nevertheless, implication of hate speech on 
individual identity development and how it impacts on other aspects of life of such a person is apparently beyond the scope of this study.

Hate speech seems different from other types of speech denotatively according to the findings of this study. This is mainly because hate speech carries a particular affective tone, a tone that adds vehemence to the insult it conveys. For this reason, hate speech may inflict a special sort of pain: the hearer learns not only that the speaker is biased against persons of his type, but also that the speaker's dislike is so intense that he has chosen to express it in terms conventionally associated with insult. The kind of painful knowledge that ethnic hate speech conveys, both denotatively and connotatively, and the various ways such knowledge can be painful is evident in the victims' responses in Wako's reports (RepublicofKenya, 2008). Such knowledge may also may be used consciously or unconsciously as the bases of the decision or judgement individuals make about the target ethnic group. The finding of this study, indicated that over $90 \%$ of the respondents believed that hate speech on social media influences individuals judgement about the target ethnic group.

The findings of this study also indicates that harsh rebukes and insults that characterise hate speech are broadly meant to silence the targets, depriving them of their freedom of speech. The claims of unequal opportunity and silencing translate into the claim that an insult of the target, even if only an epithet, carries a propositional content for an audience-for example, "Martin like all kikuyus, you are an ungrateful idiot who thinks Kenya is for Kikuyus only. You are as foolish as the rest of your tribesmen..." This kind of a propositional content might be accepted as true by the audience (other ethnic groups, as well as the speakers ethnic group) to the detriment of the target's status as a citizen or a participant in public dialogue.

Further the study's findings seem to suggest that hate speech offends by flouting social norms regarding proper verbal behaviour. The use of stereotypic epithet against specific tribes (e.g. Luos are Stone throwers (violent); Luos are Dirty; Kikuyus are Land grabbers; Kikuyus are Shrewd; and Kikuyus are selfish) is meant to demean and cause others who hear it or hear of it to lower their opinions of the targets and become more dismissive of their ideas, their accomplishments, and their needs. These kinds of expressions are speech act that shows disrespect for or even subordinates the targets. Moreover, hate speech, because it violates social norms regarding civility and respectfulness, counts as an act of incivility and disrespect. Use of vulgar language and that compared the whole community to some stigmatized phenomena e.g. jiggers, witchcraft, thieves etc. serves to exemplify this (Lægaard, 2009).

While a great majority of the respondent indicated that reading hate speech messages on social media made them feel bad about the authors of such hate messages, few felt that such utterances from an individual would make them feel as bad about the community of the source $(56.7 \%)$. This could mean that blame for hate messages emanating from individual bloggers or commentators is not always passed on to the community of that blogger. This of course negates some principles of advocates of collective moral responsibility, particularly those who argue that a whole group is liable (should be held morally responsible) for the morally faulty actions of one or several members of the group. As Feinberg (1976) observes this type of responsibility, would have been thought to work in groups possessing a significant degree of solidarity. Ethnic distinctions in Kenya, characteristically represent important axis of such solidarity. However, the findings of this study seem to suggest that even in communal societies, individual human agents can be held morally responsible for their misdeeds. Perhaps, Kenyans largely perceive themselves from an individualistic rather than a communalistic perspective.

Nevertheless, findings of this study indicate that hate speech has significant influence on how Kenyans perceive other ethnic groups. Since the contents of hate speech are always negative, the perceptions created of other ethnic groups also tend to be negative, and a reason to discredit all utterances and actions from such a group. According to TJRC (2013) ethnic stereotyping has not only been used on the political arena to discredit politicians from other communities, but it has also fuelled targeted and barbaric forms of violence against members of such communities. Concerted efforts to debunk perceptions, myths and stereotypes created by hate speech, would be needed to neutralize the impact hate speech has on Kenyans' perception of each other. Unfortunately, successive crops of politicians seem to perfect use of such negative stereotypes to acquire and hold on to power. Hate speech therefore seems to be fuelled by these stereotypes, and they in turn find expression through hate speech.

\subsection{Ethics of citizen journalism}

Citizen journalism can provide a useful way for news media to add needed voices to an increasingly fragmented and polarized media landscape by promoting "engaged dialogue" - one that involves a willingness to listen to what other people are saying and how they see the world (Smith \& Lee, 2012). In this respect, citizen journalism can challenge the conventional role of mainstream news media. A major challenge of citizen journalism practice, however, is ensuring ethical communication by the non-professionals involved. Ethical awareness and education are lacking. This study found that moral subordination and incivility were rampant and those practicing them did not seem aware that they were breaching any ethical codes. Slurs and insults in the name of freedom of expression or at the height of campaign fever indicated a populace that had no regard for ethical communication even as they practiced citizen journalism.

Recent instances, according to Roberts and Steiner (2012), suggest that strong ethics guidance is appropriate for citizen journalism. An example is the inaccurate report of Steve Job's death in 2008 by a citizen contributor to CNN's iReport. This report led to a major drop in the stock market. Steve Job died in 2011. Citizen journalism sites should therefore not just solicit for contributions from citizens, but should also take it upon themselves to guide contributors to ensure they 
are ethical. They should both emphasize the importance of ethics and also practically teach contributors how to be ethical.

\section{Solutions and Recommendations}

The fact that a significant percentage of respondents $(90.7 \%)$ believe that hate messages on digital media influences people's judgement about the ethnic groups, is of major concern. This implies that there is continued need for development and adoption of national policies that would increase ethnic integration. Greater involvement of social, religious and national institutions in the implementation of such policies would increase their success rates.

The huge amount of online conversations that allow people to air their opinion, critique, form networks around issues of interest, mobilize people around emotive issues is indicative of the wide democratic space that Kenyans are enjoying in the new constitutional dispensation. They have become citizen journalists. They report, comment on news and air their opinions on current issues through various digital platforms. There is need, therefore, for the government and other stakeholders to intensify media literacy programs in Kenya to create awareness on the ethical concerns in using the digital platforms and perhaps counter the increasing digitized ethnic hate speech in Kenya. This can be done alongside legislating laws that would check ethnic hate speech without necessarily eroding or rolling back the freedoms of expression that digital media platforms have endowed Kenya with.

Controversies like ethical issues, potency of hate speech and ethnic balancing have no easy solutions. Being ethical depends very much on the individual and willingness to respect other people's rights even as one expresses his perceived rights. Although morality is difficult to legislate, some form of legislation that criminalizes hate speech could help. The fact that less than $30 \%$ indicated that they engaged in hate speech implies that the majority of Kenyans do not practice the vice. There is need for this majority to speak up against hate speech. They could use the same digital platforms so that even for those consuming such content, there will be a balance in views, and hopefully, those against the vice will be more. As the saying goes, 'All that is necessary for evil to triumph is for good men to do nothing.'

On ethnic balancing, the authors would recommend opportunities that help train the perceived disadvantaged tribes to help them compete at par with the other tribes. Educational opportunities and scholarships would ensure that whoever gets the opportunity to serve in public office has the requisite skills. This would ensure that the development of the country is not affected by putting in office individuals without the skills to carry out the responsibilities such an office calls for.

The problem of the influence of hate speech could also be solved by good people speaking up. An awareness and educational campaign that would open up the eyes of the majority to the evil of hate speech could result in active opposition of the vice by the majority of Kenyans. The tendency by many Kenyans to avoid involvement gives a clear highway for the perpetrators to drive their agenda. Since hate speech offends by flouting social norms regarding proper verbal behaviour, it is time Kenyans take the offense personally and build public opinion against hate speech. This can be done through public education and advocacy.

Moral subordination and incivility based on ethnicity, whether at an individual or government, level is cruel and unethical. Treating an ethnic group as if their interests are intrinsically less important, and their lives inherently less valuable, than the reference group only raises bitterness that breeds retaliatory responses. Speech or action that is disrespectful or rude usually triggers a response in kind. Creating awareness so that the perpetrators know they could also be on the receiving end could stem the vice. A development in Kenya that should be encouraged is inter-tribal marriages. If people could marry outside their tribes, then a new generation not based on tribes would emerge. This would make it difficult for politicians and others who pull the tribal cards for personal gain as they would have no tribe to appeal to. It would also stop ethnic hate speech since your daughter and grandchildren could be in the 'hated' tribe. This would definitely take time, but it is a possibility.

\section{Areas for further studies}

This study focused on digitized ethnic hate speech in Kenya. Further research need to be done on other types of hate speech including racist hate speech, religious hate speech and gender. Another area that deserves further investigation is on the effects of digitized hate speech on the target individuals or groups.

\section{Conclusion}

Hate speech seems like a firmly established phenomenon on the Kenyan digital space. The findings from this study corroborates Umati report (Umati, 2013) which indicates that political events are the major triggers of ethnic hate speech in Kenya. Digitized ethnic hate speech in Kenya arises particularly when political activities like election campaigns are intensified and politicians are at war with one another. Most of the ethnic hate speech before and after 2013 general election in Kenya found its expression on the Facebook platform. The upsurge of digitized hate speech in Kenya could be as a result of increased internet connectivity, mobile phone penetration in Kenya and ever rising popularity of Facebook in the country.

This study demonstrated that digital media hate speech disseminators had varied intentions raging from inciting hatred, violence, or moral subordination among others. Nevertheless, the magnitude of incivility that accompanied hate messages on digital platform in Kenya was appalling. Hate speech, and the accompanying ethical issues it raises, are detrimental to the welfare of a nation and its people. Digitized hate speech adds speed and volume to such messages and can only be doubly destructive. 


\section{References}

Alexander, L. (2000). Freedom of speech (Vol. 1): Ashgate Pub Ltd.

Allan, S., \& Thorsen, E. (2009). Citizen journalism: Global perspectives (Vol. 1): Peter Lang.

Altman, A. (1993). Liberalism and campus hate speech: A philosophical examination. Ethics, 302-317.

Anderson, B. (2006). Imagined Communities: Reflections on the Origin and Spread of Nationalism: Verso.

Austin, J. L. (1975). How to do things with words (Vol. 367): Oxford university press.

Ayeomoni, O. M., \& Akinkuolere, O. S. (2012). A Pragmatic Analysis of Victory and Inaugural Speeches of President Umaru Musa Yar"e Adua. Theory and Practice in Language Studies, 2(3), 461-468.

Banks, J. (2010). Regulating hate speech online. International Review of Law, Computers \& Technology, 24(3), 233239.

Berger, B. A. (2003). Promoting civility in pharmacy education (Vol. 9): CRC Press.

Boeckmann, R. J., \& Turpin-Petrosino, C. (2002). Understanding the harm of hate crime. Journal of social issues, $58(2), 207-225$.

Chege, M. (2008). Kenya: back from the brink? Journal of Democracy, 19(4), 125-139.

Chege, M. (2008). Kenya: back from the brink? Journal of Democracy, 19(4), 125 -134.

Clark, C. (2008). The dance of incivility in nursing education as described by nursing faculty and students. Advances in Nursing Science, 31(4), E37-E54.

Cohen-Almagor, R. (2013). Book Review, Jeremy Waldron, The Harm in Hate Speech (Cambridge, Mass.: Harvard University Press, 2012). The Harm in Hate Speech.

Goldstein, J., \& Rotich, J. (2008a). Digitally networked technology in Kenya's 2007-2008 post-election crisis. Berkman Center Research Publication(2008-09).

Goldstein, J., \& Rotich, J. (2008b). Digitally networked technology in Kenya's 2007-2008 post-election crisis. Berkman Center Research Publication, 9.

Goldston, J. A. (2002). Roma rights, Roma wrongs. Foreign Aff., 81, 146.

Hernández, T. K. (2011). Hate speech and the language of racism in Latin America: a lens for reconsidering global hate speech restrictions and legislation models. University of Pennsylvania Journal of International Law, 32(3), 805-841.

Hout, M. (2008). How class works: Objective and subjective aspects of class since the 1970s. Social class: How does it work, 25-64.

Isajiw, W. W. (1993). Definition and dimensions of ethnicity: A theoretical framework.

Ismail, J. A., \& Deane, J. (2008). The 2007 general election in Kenya and its aftermath: The role of local language media. The International Journal of Press/Politics, 13(3), 319-327.

Kailes, J. I. (2010). Language is more than a trivial concern. Available from June.

Kante, B. (2014). International Organizations and Social Media: News, Engagement, and Social Data for Policy Change. http://www.bethkanter.org/international-orgs/\#sthash.XYFQ9Mlf.dpuf

Kimotho, S. G. (2013). Stigma Management Communication: A Case of Tungiasis in Murang'a County. Ph.D., Daystar Nairobi.

Klopp, J., \& Kamungi, P. (2007). Violence and elections: will Kenya collapse? World Policy Journal, 11-18.

Klopp, J., \& Kamungi, P. (2007). Violence and elections: will Kenya collapse? World Policy Journal, 11(18).

Lægaard, S. (2009). Normative interpretations of diversity The Muhammad cartoons controversy and the importance of context. Ethnicities, 9(3), 314-333.

Macfarlane, G. J., Lunt, M., Palmer, B., Afzal, C., Silman, A. J., \& Esmail, A. (2007). Determining aspects of ethnicity amongst persons of South Asian origin: the use of a surname-classification programme (Nam Pehchan). Public Health, 121(3), 231-236.

Montalvo, J. G., \& Reynal-Querol, M. (2010). Ethnic polarization and the duration of civil wars. Economics of Governance, 11(2), 123-143.

Musa, B. A., \& Willis, J. (2014). From Twitter to Tahrir Square: Ethics in Social and New Media Communication [2 volumes]: ABC-CLIO.

Orbach, B. (2012). On Hubris, Civility, and Incivility. Civility, and Incivility (April 26, 2012), 54, 12-14.

Perry, B. (2012). Hate and bias crime: A reader: Routledge.

Reddy, V. (2002). Perverts and sodomites: Homophobia as hate speech in Africa. Southern African Linguistics and Applied Language Studies, 20(3), 163-175. 
RepublicofKenya. (2008). The report of the Commission of Inquiry into the Post-Election Violence (the Waki report). Nairobi: Waki Commission.

Roberts, J. \& Steiner L. (2012). Ethics of Citizen Journalism sites. Retrieved on February $26^{\text {th }} 2016$ from:https://www.academia. edu/2291679/Ethics_of_Citizen_Journalism_Sites

Rosenfeld, M. (2002). Hate speech in constitutional jurisprudence: A comparative analysis. Cardozo L. Rev., 24,152

Sambanis, N. (2004). Using case studies to expand economic models of civil war. Perspectives on Politics, 2(02), 259279.

Searle, J. R., \& Vanderveken, D. (2005). Speech acts and illocutionary logic Logic, Thought and Action (pp. 109-132): Springer.

Simpson, R. M. (2013). Dignity, harm, and hate speech. Law and Philosophy, 32(6), 701-728.

Smith, D. A. \& Lee, P. (2012). A code of ethics for citizen journalism. Retrieved on February $26^{\text {th }} 2016$ from: http://www.rjr.ru.ac.za/rjrpdf/rjr_no32/a_code_of_ethics_for_citizen_journalis m.pdf

Stakic, I. (2011). Homophobia and hate speech in Serbian public discourse: how nationalist myths and stereotypes influence prejudices against the LGBT minority.

Tarhom, D., \& Miracle, O. (2013). A pragmatic analysis of victory and inaugural speeches of president jonathan: a measure for transformation and good governance in nigeria. Innovare Journal of Social Sciences.

TheDigitalRandReport. (2014). State of Social Media in Kenya. http://digitalrand.com/resources/reports/A002.pdf

Timofeeva, Y. A. (2002). Hate Speech Online: Restricted or Protected-Comparison of Regulations in the United States and Germany. J. Transnat'l L. \& Pol'y, 12, 253.

Townsend, E. (2014). Hate Speech or Genocidal Discourse? An Examination of Anti-Roma Sentiment in Contemporary Europe. PORTAL Journal of Multidisciplinary International Studies, 11(1).

Traum, A. (2014). Contextualising the hate speech debate: the United States and South Africa. Comparative and International Law Journal of Southern Africa, 47(1), 64-88.

Tsesis, A. (2001). Hate in cyberspace: Regulating hate speech on the Internet. San Diego L. Rev., $38,817$.

Tully, M., \& Ekdale, B. (2012). The team online: Entertainment-education, social media, and cocreated messages. Television \& New Media, 1527476412455952.

Umati. (2013). Monitoring Online Dangerous Speech Report (Vol. February and March 2013 ). Nairobi: Umati

Waldron, J. (2012). The harm in hate speech: Harvard University Press.

Zanghellini, A. (2003). Jurisprudential Foundations for Anti-Vilification Laws: TheRelevance of Speech Act and Foucauldian Theory. Melb. UL Rev., 27, 458. 